\title{
Understanding Syntactic and Semantic Errors in the Composition Writing of Jordanian EFL Learners
}

\author{
Yazan Shaker Almahameed (Corresponding author) \\ Department of English Language and Translation, Amman Arab University, Jordan \\ E-mail. Yazan.Shaker@yahoo.com \\ May Al-Shaikhli \\ Department of English Language and Translation, Amman Arab University, Jordan \\ E-mail: may@aau.edu.jo
}

Received: 19-04-2017

Accepted: 10-06-2017

Advance Access Published: September 2017

Published: 01-11-2017

doi:10.7575/aiac.ijalel.v.6n.6p.158

URL: http://dx.doi.org/10.7575/aiac.ijalel.v.6n.6p.158

\begin{abstract}
The current study aimed at investigating the salient syntactic and semantic errors made by Jordanian English foreign language learners as writing in English. Writing poses a great challenge for both native and non-native speakers of English, since writing involves employing most language sub-systems such as grammar, vocabulary, spelling and punctuation. A total of 30 Jordanian English foreign language learners participated in the study. The participants were instructed to write a composition of no more than one hundred and fifty words on a selected topic. Essays were collected and analyzed statistically to obtain the needed results. The results of the study displayed that syntactic errors produced by the participants were varied, in that eleven types of syntactic errors were committed as follows; verb-tense, agreement, auxiliary, conjunctions, word order, resumptive pronouns, null-subject, double-subject, superlative, comparative and possessive pronouns. Amongst syntactic errors, verb tense errors were the most frequent with $33 \%$. The results additionally revealed that two types of semantic errors were made; errors at sentence level and errors at word level. Errors at word level outstripped by far errors at sentence level, scoring respectively $82 \%$ and $18 \%$. It can be concluded that the syntactic and semantic knowledge of Jordanian learners of English is still insufficient.
\end{abstract}

Keywords: EFL learners, Syntactic errors, Semantic errors. Conjunctions, resumptive pronouns

\section{Introduction}

Writing is simply a productive skill in a written manner, where a writer generates ideas and thoughts in an organized and constructed way. Many attempts have been made by researchers to define writing, one of the most working definitions is that of White and Arndt (1991, p. 3) who state that writing is "a form of problem-solving which involves such process as generating ideas, discovering a voice with which to write, planning, goal setting, monitoring and evaluating what is going to be written, and searching with language with which to express exact meanings". Writing is deemed by many language experts as the most complicated skill for both foreign language learners and native speakers (Harris and Cunningham, 1994, Rababah, 2003, Alkhresheh, 2010). As it was described by Llach, (2011) writing is a troublesome skill for any language speakers, specifically for non-native speakers. Based on the figures obtained from National Assessment of Educational Progress (2002), roughly 69\% of eighth graders and 77\% of twelfth graders in the United States of America are not writing well. In addition, the statistics showed that 50\% of college students were unable to produce English sentences without committing errors. The above mentioned figures indicate that writing is a serious problem encountered by native and non-native speakers on a similar footing. As foreign language learners, Jordanian learners of English encounter various difficulties in English writing (Rababah, 2001, 2003; Zughoul,1991). Admittedly, Writing is highly troublesome and challenging for Jordanian English learners, since English is not widely practiced in the country in addition to the shortcomings of adopted teaching methods, which are solely based on dictating and instructing. This study highlights errors made by Jordanian English learners in order to determine how successful in writing they are. Thereby, collective efforts need to be made by language instructors, curriculum designers and officials at education sector in order to improve students' writing in the first language L1 and the second language L2 as well.

The difficulty that English language learners confronts, while producing any piece of writing lies in the following facts; first, writing requires implementing numerous complex tasks at the same time such as planning, translating, reviewing and monitoring (Hayes, Flower, Schriver, Stratman, and Carcy, 1987). In other words, the process of writing requires students to think repeatedly before putting their ideas on papers, organizing ideas and looking back and forth at their writing with a critical eye so as to produce sentences free of errors. Second, students attempting to write must be equipped with various language skills in order to generate sentences with limited errors. Students writing in L2 are 
needed to have a good command of the orthographic system of L2, including spelling and punctuation norms. Those students should be also proficient at the grammatical rules of the target language such as word order and tenses. One more requirement of writing is having a good semantic competence of L2, which involves building a large stock of vocabulary and lexical items such as idioms, collocations, proverbs and other utterances. In addition, writing depends on the genre the writer opts to use; for instance, the style of academic writing is different from that of business writing or press language. Every style of writing has its distinctive features that students should be aware of before starting the writing process, such as how to produce a model introduction, body and conclusion with a meaningful topic sentence and supporting sentences that are synthesized in a coherent manner. All the previously mentioned factors are contributing significantly to a successful writing if taken into account by L2 learners.

For the purpose of determining L2 learners' errors in writing, different language approaches were advanced. One of the most influential, practical and ever-lasting approaches is Error Analysis EA. Error Analysis elevated the status of errors from undesirability to a technique by which L2 learners build the knowledge of target language (Ellis, 1985). Unlike other L2 approaches such as Contrastive Analysis CA, Error Analysis treats errors as an important factor for teachers, in which errors inform the teacher about the progress made by students. Similarly, errors are significant for students in that errors can be utilized as a tool by which learners acquire L2 (Corder, 1967).

As reported by Corder (1974 as Cited in Ellis, 1994, p. 48) when conducting Error Analysis, three main steps need to be taken into consideration as follows: First, collection of a sample learner language: This involves determining the sample that will be utilized and collecting the data from that sample. Second, description of errors: This step requires classifying errors into different categories; omission, addition and substitution. Third, Explanation of errors: This step involves determining the sources of errors either mother tongue interference or intralingual errors. It is of a paramount significant to indicate that mother tongue errors are those resulting from first language transfer, whilst, intralingual errors are those arising from difficulty in the target language itself. Error Analysis makes a distinction between errors and mistakes. Corder (1967) contends that errors are language deficiencies resulting from lack of knowledge of L2 or incomplete acquisition of L2, whereas mistakes are language deficiencies arising from memory limitations, fatigue, slip of tongue or lack of attention. Mistakes seem to be self-correctable when the attention is paid, while errors are not.

The current study attempts to look at English foreign language EFL learners' errors in two main areas of English language namely; syntax and semantics. In other words, this study investigates syntactic and semantic errors committed by Jordanian EFL learners when writing a composition. Prior to illustrating on the sub-types of syntactic and semantic errors examined in this study, it is fitting to have an idea about those two concepts in English language. Syntax is known as " the branch of grammar dealing with the ways in which words, with or without appropriate inflections, are arranged to show connections of meaning within the sentence" (Matthews, 1982, p. 1 as cited in Valin, 2001). Based on the above mentioned conceptualization of syntax, this study examines all errors made by the learners within the context of word order, inflections, auxiliary, subject-verb agreement and tense. On the other hand, semantics refers to "the meaning of words and sentences and to the rules or constraints by which the meanings of sentences are built from the meanings of words" (Allan, 2009, p. 972). With reference to the aforementioned definition, the present study endeavors to uncover errors relevant to the meanings of words (misuse of words) and meanings of sentences (miss-translation). Examining one type of errors, e.g. semantic errors would tell half of the story, whilst Placing the emphasis on the two types of errors would provide a deeper insight into the difficulties encountered by EFL learners while writing English composition. Thereby both syntactic and semantic errors are considered in this study.

\section{Review of Related Literature}

Previous studies investigated errors made by L2 learners in writing are diverse. Some studies place their emphasis on errors from a syntactic perspective, whereas other studies highlight semantic errors. Some more studies unveil errors related to morphological or phonological use of language. This review of literature highlights research studies examine all grammatical errors with more emphasis on syntactic and semantic errors among learners whose native language is Arabic. The goal of this review of literature is to gain additional insight into the nature of writing errors committed by Arab learners of English in terms of types of those errors and their possible sources.

One of the first efforts to analyze syntactic errors among Arab learners of English is a study conducted by Abdul-Fattah and El-Hassan (1993). The researchers aim primarily to identify and explain some syntactic errors committed by $15-$ year old school children in Jordan with the ultimate goal of developing teaching process at public schools. A total of 320 students take part in the study, covering ten districts in the country. A 100-item test is administered to the participants, split into two parts with 50 items for each. The study arrives at the following findings; first, transfer from Arabic is a genuine cause of syntactic errors made by the participants, where $30 \%$ of errors can be ascribed to native language transfer. Second, syntactic errors committed by the participants are varied as follows; errors in the use of comparative, superlative, tense, word order, prepositions, lexis, interrogatives, pronouns and determiners. It was also found that errors in the use of tense are the most frequent among respondents with $20 \%$, while errors in the use of comparativelsuperlative are the least with only $3.5 \%$. The researchers conclude that the participants performed poorly nearly in all syntactic categories under investigation, which calls for improving the pedagogical system in Jordan.

Hourani (2008) investigates the grammatical errors in the English writing by third secondary students in Emirates schools. The study aims chiefly at fulfilling two main objectives; first, exploring the most frequent grammatical errors made by the respondents and second, determining the sources of these errors. In collecting the required data for the study, three instruments are employed. First, interview, in which five English supervisors are interviewed to obtain data about students' grammatical skills. Second, a composition, in which the students are asked to write an essay to measure 
their English grammatical knowledge. Third, Two-part questionnaire; one part is administered to English teachers, while the another to students. The sample of the study consists of 115 students aged between 17 and 18 years. The findings reveal that the Emirati learners of English commit numerous grammatical errors including; passivization, verb tense and form, subject-verb agreement, word order, prepositions, articles, plurality and auxiliaries. The results further display that most grammatical errors are owing to intralingual interference rather than interlingual interference. Finally, the researcher suggests to improve students' writing skill due to their poor performance on the composition test.

Sharing Hourani's results, Al-Shormani and Al-Sohbanil (2012) explore the semantic errors among Yamani undergraduates. The study aims at fulfilling two main objectives; first, examining the most common semantic errors committed by the respondents. Second, looking at all possible sources of these errors. The semantic errors identified in this study are classified into three broad categories, namely, lexical, collocation and lexico-grammatical. Each of these categories is further grouped into subcategories depending on the errors identified. Thirty undergraduate Yemeni students majoring in English language partake in the study. In collecting the needed data for the study, thirty essays are distributed to the participants. It was found that 1388 semantic errors identified, 251 of which are attributed to deletion of letters category, constituting the largest portion of errors, scoring $18 \%$, whereas miss-selection of a prefix category is the lowest, accounting for $0.6 \%$ of errors. It was further found that there are two main sources of errors, namely native language -based errors and second language-based errors. To be more specific, errors resulting from native language include translating concepts, words and phrases literally from L1, i.e. Arabic into English and applying Arabic linguistic rules to English. In addition, errors owing to target language include having false concepts about English, insufficient knowledge of English semantic system and confusion about English vocabulary.

In a similar vein, Alhassan (2013) implements a research paper on the influence of Arabic as a native language on the writing of Jordanian learners of English. The study aims basically at determining whether fist language transfer is the chief cause of errors committed by the learners and identifying any other possible sources of errors. Errors made by the participants are identified and described using Error analysis procedures. For the purpose of achieving the objectives of the study, essay-writing test and 50-item placement test are utilized. Students' errors are tabulated into three main categories as follows; grammatical errors, semantic errors and syntactic errors. The results of the study depict that the participants commit several errors as reported; first, grammatical errors including parts of speech such as prepositions, articles and adjectives. Second, semantic errors such as literal translation and 3- syntactic errors comprising coordination, omission of copula and word order. The results of the study further reveal that a considerable amount of learners' errors are attributable to native language transfer.

In line with Alhassan's study, Al-Khasawneh (2014) carries out a study on errors made in written English paragraph by Jordanian university students. The researcher seeks primarily to investigate the writing errors committed by Jordanian EFL learners at Ajloun National University when writing English paragraphs. As a secondary objective, the study aims to identify the frequency of writing errors made by Jordanian EFL learners at Ajloun National University when writing English paragraphs. For the purpose of obtaining the required data, 26 undergraduates are asked to write an essay on the importance of education. The researcher arrives at the conclusion that the students commit several errors such as: spelling, word order, and subject-verb agreement. The findings additionally show that the most common error made by the respondents is the faulty usage of English articles.

Based on reviewed literature, one could say that Arab speakers of English confront serious difficulties in English writing. The results of past studies strongly support the premise that Arab EFL learners commit various errors including all sub-systems of English language, e.g. syntax, semantics, etc. It has been agreed, there is no one source of those errors, where some errors arising from first language transfer and other errors arising from second language. In simple words, both first language and second language work in tandem in the acquisition of the target language. Within the context of the present study, both syntactic and semantic errors are analyzed thoroughly in order to gain knowledge on their nature and sources.

\section{Statement of the Problem}

When acquiring a second language, L2 speakers are required to master the four skills constituting any language; speaking, writing, reading and listening. One of the most significant skills is writing (Huy, 2010), which is deemed indispensable requirement for L2 learning. L2 learners, who wish to express themselves well, convey their messages properly and translate into L2 with an organized manner, should not write poorly. During the course of teaching English either at schools or universities in Jordan, which extended for ten years, it was noticed that many Jordanian EFL learners performed poorly in writing. This is in line with Al-Khresheh (2010), who states that although Jordanian students study English for a long period, extending for twelve years at school, they keep committing errors in their writing. Some other researchers (Al-Khataybeh, 1992; Rababah, 2001, 2003; Zughoul, 1991, 2003) argue that Jordanian EFL learners lack the knowledge in all language skills, and writing constitutes the greatest learning difficulty for those learners. Sharing the same view, Tahaineh (2010) points out that despite the many attempts to tackle writing difficulties encountered by Arab Jordanian EFL learners, writing is still a problem impedes acquiring the target language. It is fitting to say that most previous studies, did not examine the two language categories (syntax and semantics) together, but separately. The present study bridges a gap in literature by placing adequate emphasis on both syntactic and semantic aspects of language. By so doing, through understanding of the nature of errors can be achieved and in turn a better explanation of learners' errors is presented. Thereby, this study provides detailed explanation of all errors' types together with illustrative examples. 


\section{Objectives of the Study}

The present study aims at fulfilling the following objectives.

First, investigating syntactic errors encountered by Jordanian EFL learners in composition writing.

Second, investigating semantic errors encountered by Jordanian EFL learners in composition writing.

\section{Research Questions}

The present study raises the following research questions

Question One: What are the salient syntactic errors encountered by Jordanian EFL learners in composition writing?

Question Two: What are the salient semantic errors encountered by Jordanian EFL learners in composition writing?

\section{Methodology}

\subsection{Design of the Study}

According to Riazi (2016, p. 275). " research design refers to how the researchers plan their studies so that they can obtain answers to the stated research questions using systematic approaches". In the present study, descriptive method is used in order to gain insight into the nature of syntactic and semantic errors made by the participants. More precisely, descriptive statistics are employed in which percentage and frequency of syntactic errors are tabulated, then the percentage and frequency of semantic errors are categorized.

\subsection{Participants}

A total of 30 Jordanian EFL students at The Hashemite University participated in the study in the fall semester during the academic year 2016 2017. The participants are all majored in English language and ranging from second to fourth academic year. The subjects are comprised of both males and females aged between 19-20 years. Factors such as gender or academic level are not considered in this research study. All participants have studied English for twelve years before joining the university; therefore, they are exposed to English as L2 at a similar level. The sample is selected randomly using simple random sampling method in order to guarantee fair chance of participation.

\subsection{Instruments}

In obtaining the needed data for the current research study, a composition test is utilized. The participants are instructed to write an essay of no more than one hundred and fifty words on one of the following four topics; 1 - Describing the first house you grew in, 2- Narration on the first day at university 3. Moms' right of granting their nationalities to children and 3- what will you change in the world if you have the power to do so?. They are asked to conform with the style of writing a model essay such as splitting the essay into paragraphs and using punctuation marks. Having collected the essays from the participants, they are analyzed statistically to obtain the results for the purpose of this study.

\section{Findings}

Errors committed by the participants are detected and then tabulated into two main types; first syntactic errors and second, semantic errors. Following that, the errors related to each types are further classified into different categories. This review of findings starts with syntactic errors made by the respondents in order to answer research question one " What are the salient syntactic errors encountered by Jordanian EFL learners in composition writing?". A total of 172 syntactic errors are committed by the respondents. The errors include the following sub-categories, namely; subjectverb agreement, tense, auxiliary, null subject, double subject, resumptive pronouns, word order, conjunctions, superlative, comparative and possessive pronouns. Table 1 below displays the frequency and percentage of syntactic errors in the writing of Jordanian EFL learners.

Table 1. Syntactic errors made by Jordanian EFL learners.

\begin{tabular}{lll}
\hline Item & Frequency & Percentage \\
\hline Verb-tense & 56 & $33 \%$ \\
Agreement & 48 & $28 \%$ \\
Auxiliary & 17 & $10 \%$ \\
Conjunctions & 12 & $7 \%$ \\
Word Order & 11 & $6 \%$ \\
Resumptive pronouns & 10 & $6 \%$ \\
Null-subject & 9 & $5 \%$ \\
Double subject & 5 & $3 \%$ \\
Superlative & 2 & $1 . \%$ \\
Comparative & 1 & $0.5 \%$ \\
Possessive pronouns & 1 & $0.5 \%$ \\
\hline
\end{tabular}


A close look at Table 1 above reveals that the highest proportion of syntactic errors is in the use of verb tense with a percentage of $33 \%$ and a frequency of 56. It is also obvious from this table that lowest proportion of syntactic errors is in the use of both comparative and possessive pronouns with a percentage, $0.5 \%$ and frequency 1 . Having depicted the statistics of syntactic errors, the percentage and frequency of semantic errors are revealed in table 2 below in order to answer research question two "What are the salient semantic errors encountered by Jordanian EFL learners in composition writing?". It is of a paramount importance to indicate that semantic errors are split into two main levels; 1 errors committed at word level, which is also termed as miss-use of words and errors committed at sentence level, which termed as miss-use of sentence as shown in Table 2 below.

Table 2. Semantic errors made by Jordanian EFL learners

\begin{tabular}{lll}
\hline Item & Frequency & Percentage \\
\hline Errors at word level & 137 & $82 \%$ \\
Errors at sentence level & 29 & $18 \%$ \\
\hline
\end{tabular}

Based on the results obtained from Table 2 above, one could conclude that a total of 166 semantic errors made by the participants, 137 of which are at word level, while 29 are produced at sentence level. In addition, the table indicates that the vast majority of errors are related to miss-use of words with $82 \%$, whereas $18 \%$ of errors are associated to miss-use of sentence

\section{Discussion of Findings}

This part of the study discusses with some illustrative examples the syntactic and semantic errors made in the writing of learners. This discussion of results aims principally at highlighting the errors and analyzing them in terms of their sources and occurrence.

\subsection{Syntactic Errors}

As it has been indicated previously, several types of syntactic errors arose when writing in English, progressing from verb-tense to possessive pronouns. A sample of learners' errors will be analyzed. The beginning will be with verb-tense errors.

\section{Verb-tense}

\section{Example: I met a girl and I talk to her then she becomes my best friend.}

In the aforementioned example, two tense errors were committed with the verbs, talk and become. More specifically, the tense of the sentence is the past, however, the respondent kept using the present tense in referring to the past. This error could be attributed to intralingual interference or difficulty of the target language itself so that the respondent got confused due to the various tenses in English

\section{Agreement}

Example: *The house contain a three rooms

In the example above, two types of agreement errors were committed. The first one is subject-verb agreement e.g. *the house contain, where the respondent dropped the $s$ that marks verbs after singular nouns. The second type is the addition of indefinite article $a$ with plural noun e.g. a three rooms. Those errors are purely intrallingual in nature as the agreement system in both English and Arabic is totally different.

\section{Auxiliary}

Example: *The Hashemite university very large

This type of error is characterized by the deletion of the auxiliary is from the sentence. Such deletion of auxiliary with no doubt is attributed to first language transfer as Arabic, respondents' first language does not have auxiliaries in its system.

\section{Conjunctions}

Example: *I woke up early I was very excited.

This type of errors is exhibited by the omission of the conjunction and. When writing a compound sentence, the conjunction and serves the function of joining two clauses together. This error is intralingual in nature rather than interlingual

\section{Word Order}

\section{Example: * There are things beautiful in the university}

From the above example, it is obvious the respondent misplaced the noun things and the adjective beautiful. It is generally agreed that in English adjectives modifying a noun placed prior to the noun. The source of this error is Arabic (first language) due to the fact that, in Arabic nouns precede adjectives.

\section{Resumptive pronouns}

Example: *My grandfather house which I save it in my memory. 
This type of errors is best manifested by adding unnecessary pronoun referring to the subject in the sentence. In the example above, the respondent added the resumptive pronoun it after the verb save making the sentence ungrammatical. This error can be traced back to Arabic, since the use of resumptive pronouns in Arabic is licit.

\section{Null-Subject}

\section{Example: * All my life lived in one house}

At first sight, it is evident that the subject in the sentence above is missed, which is ungrammatical in English because English is a non-null subject language. This type of errors is ascribed to native language as Arabic permits implicit subject in the sentence

\section{Double Subject}

Example: My first day at the university it was good

The error in this sentence is committed as a result of adding unnecessary subject 'the pronoun it', as the subject my first day is already mentioned at the onset of the sentence. Double-subject phenomenon is prohibited in English. This error is intralingual since double subject is disallowed in Arabic either.

\section{Superlative}

Example: my sister was the beautiful between us

In the sentence above, the respondent omitted the adverb most, which is normally placed in front of adjectives to express superlative. The source of this error is difficulty of English itself.

\section{Comparative}

Example: It was big house than the house I live in now.

The error in the sentence above was caused by dropping the suffix er following the adjective big when expressing comparative. This error is intralingual in nature

\section{Possessive pronouns}

Example: The third room was me.

Instead of using the possessive pronoun mine, the respondent used the pronoun me which is disallowed. Such error can be ascribed to intralingual interference. It is of a paramount importance to indicate that the results of research question one are in agreement with the following previous studies (Abdul-Fattah and El-Hassan, 1993; Hourani 2008; Alhassan 2013; Al-Khasawneh 2014). The results of those studies clearly indicate that the respondents committed all types of syntactic errors including subject-verb agreement, word order, superlative, comparative, tense, pronouns and determiners. Those studies also denote that both first language transfer and intralingual interference are responsible for the occurrenc of errors unevenly.

\subsection{Semantic Errors}

Two types of semantic errors are noticed in the writing of the participants; namely errors at word level and errors at sentence level. Those two types of errors result from literal translation into English or mis-analogy between English and Arabic. Another source of semantic errors could be lack of knowledge of English or what is termed intralingual interference.

\section{Errors at word level}

\section{Example *The bathroom becomes on the left of house.}

The error in the above mentioned example is exhibited in the miss use of the verb become. More precisely, instead of saying the bathroom is located or found on the left, the verb become is used, which is traced back to literal translation from Arabic.

\section{Example* He reached me to the house}

The error in the aforementioned example is in the use of the verb reach. The verb reach was erroneously used to express the notion of picking up by car or giving ride. This error can be attributed to literal translation from Arabic.

\section{Example *That day was so tired.}

Based on the previous example, it is evident that the adjective tired was mistakenly used. In English, Adjectives ending with the suffix $e d$ are used to describe a feeling or emotions of someone, while adjectives ending with ing are used to describe the characteristics of things or a situation. The above mentioned example is ascribed to lack of knowledge of English.

\section{Errors at sentence level}

Example * Studying in the same at university.

This sentence appears wrong at both syntactic and semantic levels. When it comes to semantics, the sentence does not make any sense at all due to using the prepositions in and at inappropriately. This error could be ascribed to lack of knowledge of English. 
A close look at the previously stated sentence shows that the sentence is incomprehensible and meaningless due to adding some words wrongly such as decided and from. Such poor use of language arising from incomplete acquisition of English language.

Example* I could not found my class at the first.

It is apparent from this sentence that many errors were made. Precisely, the verb found was used instead of find and at the first in place of at first. In addition, the findings of research question two are consistent with those of (Al-Shormani and Al-Sohbani1, 2012; Alhassan, 2013) who point out that semantic errors include mis-use of English words and literal translation from native language. It was also indicated that both native language (Arabic) and difficulty of second language (English) are the main sources of errors.

\section{Conclusion}

To sum up, one could say that Jordanian EFL learners committed numerous syntactic and semantic errors. Syntactic errors produced by the participants included the following categories; verb-tense, agreement, auxiliary, conjunction, word order, resumptive pronouns, null-subject, double-subject, superlative, comparative and possessive pronouns. In contrast, semantic errors included two categories; namely errors at sentence level and errors at word level. As for syntactic errors, the results of the study revealed that verb-tense errors were the most common, whereas comparative errors and errors in possessive pronouns were the least. In addition, the results showed that semantic errors at word level outnumbered by far errors at sentence level. Errors produced by Jordanian EFL learners were discussed and analyzed thoroughly in this study in order to enhance our understanding of the nature and sources of those errors. That is to say, both L1 transfer and intralingual interference work in a close connection in shaping the syntactic and semantic knowledge of Jordanian learners of English.

\section{References}

Abdul-Fattah, H. and El-Hassan, S. (1993). Syntactic Errors of Jordanian School-Children in English: The Role of the Native Language. Yarmouk University. Jordan.

Alhassan, A. (2013). The Effects of Arabic on English Writing of Petra University Students. Journal of Modern Education Review, 3(3).

Al-Khasawneh, F. (2014). Error Analysis of Written English Paragraphs by Jordanian Undergraduate Students: A Case Study. The International Journal of English Language, Literature and Humanities, 2(4).

AL-Khataybeh, M. (1992). An analysis of syntactic errors in the composition of Jordanian tenth grade students. Unpublished M.A. thesis. Yarmouk University-Jordan.

Alkhresheh, M. (2010). "Interlingual interference in the English Language Word Order Structure of Jordanian EFL Learners". European Journal of Social Science, 16(1), 105-116.

Allan, K. (2009). Concise Encyclopedia of Semantics.UK. Elsevier

Al-Shormani, M and Al-Sohbani1, Y. (2012). Semantic Errors Committed by Yamani University Learners: Classifications and Sources. International Journal of English Linguistics, 2(6).

Corder, S.P. (1967). The significance of Learners Errors. Interactional Review of Applied Linguistics, 9, 161-170.

Ellis, R. (1985). Understanding Second Language acquisition. New York. Oxford University Press.

Ellis, R. (1994). The Study of Second Language Acquisition. New York. Oxford University Press.

Harris, G. J., and Cunningham, H. D. (1994). The Simon and Schuster guide to writing. New Jersey: Prentice Hall, Englewood Cliffs.

Hayes, J. R., Flower, L., Schriver, K., Stratman, J., \& Carey, L. (1987). Advances in applied psycholinguistics. Vol. 2. Reading, writing and language processing S. Rosenberg, Ed. Cambridge, England.

Hourani, T. (2008). An Analysis of the Common Grammatical Errors in the English Writing made by 3rd Secondary Male Students in the Eastern Coast of the UAE. M.A Thesis. British University in Dubai.

Huy, N. (2015). Problems affecting Learning Writing Skill of Grade 11 at Thong Linch High School. Asian Journal of Educational Research, 3(2).

Liatch, M. (2011). Lexical Errors and Accuracy in Second Language Writing. UK. MPG Books Group.

Rababah, G. (2001). An investigation into the strategic Competence of Arab Learners of English at Jordanian Universities. PhD Dissertation University of Newcastle uponTyne.UK.

Rababah, G. (2003). "Communication Problems Facing Arab Learners of English: A personal Perspective ". TEFL Web Journal, 2(1), 15-27.

Riazi. M. (2016). The Routledge Encyclopedia of Research Methods in Applied Linguistics: Quantitative, Qualitative and Mixed Methods Research. New York, Routledge Tylor \& Francis Group.

Tahaineh. Y (2010). Arab EFL University Students' Errors in the Use of Prepositions. MJAL2:1JANUAR. ISSN 09748741.

Valin, R. (2001). An Introduction to Syntax. UK. Cambridge University Press.

White, R., and Arndt, V. (1991). Process writing. London, UK: Longman.

Zughoul, M.R.(1991). Error in lexical choice: towards writing problematic World Lists. IRAL, 29(1), 45-60.

Zughoul, M.R.\& Hussein, A. (2003).Translational collocation strategies of Arab learners of English: a study in lexical semantics. Babel, 49(1), 59-81. 